Vol. 1, No. 1, 45-48

\title{
HERBAL DIETARY SUPPLEMENT - A MODERN APPROACH IN COMPLEMENTARY AND ALTERNATIVE MEDICINE (CAM) IN HEALTH CARE SCIENCE.
}

\author{
Debasish Sahoo ${ }^{*}$, Virendra Vaishnav ${ }^{2}$, Tanushree Chatterjee ${ }^{3}$, Navita Gupta ${ }^{4}$. \\ ${ }^{1 *}, 2$ PhD Scholar, Department of Biotechnology, CSVTU, Bhilai, C.G. India \\ ${ }^{3}$ Department of Biotechnology, RITEE, Raipur, C.G. India \\ ${ }^{4}$ Department of Life science, BBMKU, Dhanbad, Jharkhand, India \\ sahoodebasish3125@gmail.com,BK5473@csvtu.ac.in
}

\begin{abstract}
Preliminary pharmacological study of herbal based dietary supplement formulation based on extracts or whole plants derived from fruits, root, berries, macrofungus and leaves as a promising, safe and effective alternative to synthetic and pharmaceutical dietary supplements, in-vitro studies such as antibacterial, anti-oxidant and anti-inflammatory activity for extract of dietary supplements.

Nutritional assessment of nutritional attributes as suggested by AOAC method, Phytochemical analysis by standard chemical procedures, Quantitative estimate Alkaloid, Flavonoid, Phenolic, Tannin. In-vitro studies of anti-microbial (well diffusion), anti-oxidant assay (DPPH assay), antiinflammatory assay (albumin denaturation assay). FTIR analysis for detection of different functional group.

The finding suggest that the plant extract have a better nutritional aspect. The extracts for the food supplement showed positive results for anti-microbial, anti-oxidant and anti-inflammatory activity.

More studies has to be concluded in respect to in-vivo tests that will conclude other pharmacological aspect of the food supplements. Reduced concentration of heavy metals and other contaminants will increase the therapeutical potency of the supplement. Stability, hold time study, dose and dosage form must be concluded in respect to achieve maximum efficacy.

The herbal dietary supplement tend to better option against chemical based multi-vitamins and dietary supplements. These will enact the general well-being along with other pharmacological activities due to presence of phytochemicals present in the supplement.
\end{abstract}

Keywords: anti-microbial, anti-oxidant assay, anti-inflammatory assay, herbal dietary supplement.

\section{Introduction}

Herbal dietary supplement is a non-conventional health-care practice that had gained enormous interest and support which can be able to treat mental and physical weakness and has expanded its interest and application globally and gained popularity worldwide. According to the WHO 2005 . global survey there has been a marked increase in consumption of herbal products and dietary supplements in many developed and developing countries.

\section{Hypothesis Development}

Preliminary pharmacological study of herbal based dietary supplement formulation as a promising, safe and effective alternative to synthetic and pharmaceutical dietary supplements.

\section{Materials And Methodology Formulation development:}

Present study is based on an herbal dietary supplement which is a mix of hydro-alcoholic or aqueous extract of whole root Maca root (Lepidium meyenii), whole root of Siberian Ginseng The $1^{\text {st }}$ Conference On Public Health and Medical Sciences (ICOPHMEDS) 2021 
(Eleutherococcus senticosus), whole thallus of macro fungi Ganoderma lucidum, and whole leaves Moringa (Moringa oleifera). The formulation for herbal dietary extract powder constituted $59 \%(\mathrm{w} / \mathrm{w})$ of Moringa (Hydro-alcoholic extract), 17\% (w/w) of Ganoderma (aqueous extract), 13\% (w/w) of Siberian ginseng (hydro-alcoholic extract) and 11\% of Maca root (aqueous extract).

Determination of Nutritional aspects of dietary supplements: The different attributes that were analysed for herbal dietary supplements were Energy, Total carbohydrate, Total fat, Protein, Dietary fibres, Vitamins, minerals and contaminants such as heavy metals.

Qualitative screening of Plant secondary metabolites: Various chemical based tests were performed for screening of presence/absence of Plant secondary metabolites (Aiyegoro and $\underline{\text { Okoh }}$ $\underline{2010)}$.

Quantitative estimation of metabolites: Quantitative estimation Alkaloid (Shamsa et al. 2008), Flavonoid (Ramos et al. 2017), Phenolic (Amarowich et al. 2009) and Tannin (Polshettiwar et al. 2007) was estimated from their respective standard curve of Atropine, Quercetin, Gallic acid and Tannin acid respectively. The known quantity of respective standards were taken and the experiment was carried out in their respective methodologies. The standard curve was plotted as y axis $=$ Absorbance value; $\mathrm{x}$ axis $=$ Concentration of standard $\mu \mathrm{g} / \mathrm{mg}$ extract. So the unknown concentration of phytochemicals can be deduced as equation 1

$$
\text { concentration }(\mathrm{x})=\frac{y-c}{m} \quad \text { Equation } 1
$$

Invitro studies: Invitro studies such as Antimicrobial assay by well diffusion method (Balouiri et al. 2016), antioxidant assay by DPPH method (Brand-Williams et al. 1995); Phophomolybdate assay (Bursal et al. 2011) and anti-inflammatory assay by albumin denaturation assay (Mizushima et al. 1968) was also conducted for the formulated herbal dietary supplement.

\section{Results \\ 4.1 Phytochemical studies}

of the herbal dietary supplement mix showed presence of Alkaloids, Flavonoids, Phenols, Tannins, Steroids, Carbohydrate, Proteins.

\subsection{Quantitative estimation}

of Total Alkaloid (2.59 $\pm 0.16 \mathrm{mg}$ atropine/g), Total Flavonoid (21.99 $\pm 0.31 \mathrm{mg}$ Quercetin $/ \mathrm{g})$, Total phenolic (47.87 $\pm 0.39 \mathrm{mg}$ gallic acid/g) and Tannin content $(1.97 \pm 0.17 \mathrm{mg}$ tannic acid $/ \mathrm{g})$ that were expressed as $\mathrm{mg}$ of reference standards equivalents (atropine, quercetin, gallic acid, tannic acid) per gram of dried extract.

\subsection{The nutritional aspect}

of the herbal dietary supplement was tested in a NABL certified laboratory where different parameters were analyzed such as Energy value of $389.98 \mathrm{kcal} / 100 \mathrm{gm}$, Total Dietary fiber content of $18.75 \mathrm{gm} / 100 \mathrm{gm}$, Total Protein $23.89 \mathrm{gm} / 100 \mathrm{gm}$, Total fat $2.24 \mathrm{gm} / 100 \mathrm{gm}$ and Total carbohydrate $77.76 \mathrm{gm} / 100 \mathrm{gm}$. All the results analysed were carried out NABL certified laboratory facility at Hyderabad, India.

4.4 The invitro studies were also studies for the dietary supplements

\subsubsection{The antimicrobial activity}

was carried out where better activity was shown against E.coli, Salmonella sp, Clostridia sp., Pseudomonas sp., Staphylococcus . Likewise better activity was studied against Aspergillus sp. 


\subsubsection{The antioxidant activity}

was studied for herbal dietary extract mix $(0.1 \mathrm{mg} / \mathrm{ml})$ with respect to Ascorbic acid as standard $(0.1 \mathrm{mg} / \mathrm{ml})$. The antioxidant activity analyzed by DPPH assay for herbal dietary extract mix was found to be $66.87 \pm 1.78 \%$ of inhibition as compared to $79.38 \pm 1.47 \%$ for standard ascorbic acid. Phosphomolybdate assay was also carried out for antioxidant activity where the herbal dietary extract mix had $42.47 \pm 0.46 \%$ of inhibition as compared to the $48.96 \pm 0.54 \%$ of inhibition for standard ascorbic acid.

\subsubsection{The anti-inflammatory}

activity by inhibition of Albumin denaturation assay was studied for herbal dietary extract mix $(0.1 \mathrm{mg} / \mathrm{ml})$ with respect to indomethacin as standard $(0.1 \mathrm{mg} / \mathrm{ml})$. The anti-inflammatory activity of the standard was $73.09 \% \pm 1.94 \%$ whereas the sample have $58.73 \% \pm 1.47 \%$.

\section{Limitations}

Safety and efficacy might be a concern and can be regulated under FDA. The process for registration and market pre-approval of Herbal dietary supplement should be smooth enough. The new submission for registration should by case-by-case due to due to the compositional diversity and complexity of botanical substances. A mandatory post-market report for adverse cases should be documented and reported for development of more efficient and safer alternatives.

\section{Conclusion}

Herbal supplements are much safer, reliable and limited/no toxicological evidence. But still in vivo clinical trials to be conducted on various combination to obtain better dietary supplements that not only conclude for better nutritional substitution but also target and cure illness and ailments more prelevant in society. Personalized herbal supplements can also be developed that caters the need in accordance to race, ethinicity, demographic distribution and life style of individual with reference to their history of nutritional requirement and ailments.

\section{References}

Amarowich, R., Weidner, S. (2009) Biological activity of grapevine phenolic compounds. In: Roubelakis-Angelakis, K. A. (ed.) Grapevine Molecular Physiology and Biotechnology. Springer Science+Business Media B.V., pp. 389-405.

Aiyegoro, O.A., Okoh, A.I. Preliminary phytochemical screening and In vitro antioxidant activities of the aqueous extract of Helichrysum longifolium DC. BMC Complement Altern Med 10, 21 (2010). https://doi.org/10.1186/1472-6882-10-21.

Balouiri M, Sadiki M, Ibnsouda SK. Methods for in vitro evaluating antimicrobial activity: A review. J Pharm Anal. 2016 ; 6(2) : 71-79. Doi:10.1016/j.jpha.2015.11.005.

Brand-Williams W, Cuvelier ME, Berset C: Use of free radical method to evaluate antioxidant activity. Lebensmittel-Wissenschaft und-Technol 1995, 28:25-30.

Bursal E, Gulcin I: Polyphenol contents and in vitro antioxidant activities of lyophilized aqueous extract of kiwifruit (Actinidia deliciosa). Food Res Int 2011, 44:1482-1489.

Mizushima Y, Kobayashi M. Interaction of anti-inflammatory drugs with serum proteins, especially with some biologically active proteins. J Pharm Pharmacol. 1968 Mar;20(3):169-73. Doi: 10.1111/j.2042-7158.1968.tb09718.x. PMID: 4385045. 
Polshettiwar SA, Ganjiwale RO, Wadhaer SJ, Yeole PG. Spectrophotometric estimation of total tannins in some ayurvedic eye drops. Indian Journal of Pharmaceutical Sciences, 69.4, 2007, 574.

Ramos RTM, Bezerra ICF, Ferreira MRA, Soares LAL. Spectrophotometric Quantification of Flavonoids in Herbal Material, Crude Extract, and Fractions from Leaves of Eugenia uniflora Linn. Pharmacognosy Res. 2017;9(3):253-260. Doi:10.4103/pr.pr_143_16.

hamsa F., Monsef H., Ghamooshi R. and Verdian-rizi M.,: Spectrophotometric determination of total alkaloids in some Iranian medicinal plants, Thai J.Pharm. Sci. 32 (2008) 17-20.

World Health Organization. (2005). National policy on traditional medicine and regulation of herbal medicines: Report of a WHO global survey. 